\title{
Um modelo para controle biológico de pragas associado ao uso de pesticida
}

\author{
Adriane Frank, Diomar Cristina Mistro \\ Programa de Pós Graduação em Matemática, Departamento de Matemática, CCNE, UFSM \\ 97105-900, Santa Maria, RS \\ E-mail: adrianefrank@gmail.com , dcmistro@gmail.com
}

\begin{abstract}
Resumo: Neste trabalho propomos um modelo do tipo Redes de Mapas Acoplados para estudar um sistema presa-predador no qual a presa é uma praga e o predador é um agente de controle biológico. Consideramos que a estratégia de controle biológico da praga é combinada com o uso racional e planejado de pesticidas. Isto é, a substância química é utilizada apenas quando a densidade de presas atinge o limiar de dano. Além disso, a aplicação do químico é feita apenas do sítio de alta infestação da praga. Na ausência do químico, presas e predadores se movimentam por difusão. No entanto, quando a substância é aplicada, os indivíduos têm um comportamento de fuga e se locomovem de sítios com altas concentrações do químico para outros com concentrações mais baixas. A substância química, por sua vez, se espalha por difusão e pelo vento. Os resultados de simulações mostram que o limiar de presas que controla a aplicação do químico pode ter grande efeito na dinâmica do sistema e, portanto, na eficácia do controle biológico.
\end{abstract}

Palavras-chave: presa-predador, substância química, rede de mapas acoplados, dinâmica espaçotemporal, controle biológico.

\section{Introdução}

Há registros de que o uso de produtos químicos no controle de pragas com o intuito de melhorar o rendimento da produção ocorre há mais de 4000 anos. No entanto, o uso de substâncias químicas pode acarretar vários problemas: o desenvolvimento de resistência por parte de algumas espécies a certos produtos químicos, problemas à saúde humana devido ao acúmulo de resíduos nos alimentos, extinção de espécies benéficas para a biodiversidade, poluição de solo e da água, entre outros (Nerio et al., 2010).

Por esses motivos, tem-se buscado formas alternativas para controle de pragas como, por exemplo, o uso de agentes biológicos, repelentes naturais como os óleos vegetais e o uso racional e estratégico de pesticidas (Nerio et al., 2010).

O objetivo não é extinguir a população de pragas (Rodrigues et al., 2012) mas sim manter a sua densidade em níveis que não causem prejuízo econômico ao produtor. Desta forma, vamos estudar a estratégia combinada de controle biológico da praga através de um predador com o uso racional e planejado de pesticidas. Isto é, vamos analisar a dinâmica do sistema supondo que o químico é aplicado apenas nas regiões e nos momentos em que a densidade de presa (praga) está acima do limiar de danos à plantação.

Propomos um modelo do tipo Rede de Mapas Acoplados (RMA) a fim de analisar a dinâmica espaço-temporal do sistema presa-predador-pesticida. Nosso objetivo é analisar a distribuição espacial e a persistência de presas e predadores quando a estratégia combinada descrita acima é aplicada.

Na formulação de um modelo RMA, o domínio é dividido em sítios discretos onde a população está distribuída. A dinâmica é composta de duas fases distintas: a fase de movimentação e a fase de reação. Durante a fase de movimentação, uma fração de indivíduos se locomove para os 
sítios mais próximos enquanto a fração restante permenece no sítio original. Na fase de reação acontecem todas as interações intra e inter específicas (Hassell et al., 1991).

Para construir o modelo, consideramos as seguintes hipóteses:

- Presas e predadores se movimentam por difusão na ausência do pesticida;

- Ambas espécies fogem para os sítios vizinhos em resposta à concentração da substância química ;

- A substância química se dispersa por difusão e por convecção;

- Presas crescem logisticamente na ausência dos predadores;

- Predadores dependem exclusivamente da espécie de presas;

- Quando a densidade de presas atinge o limiar de dano em um sítio, o pesticida é aplicado apenas neste sítio;

- Ambas espécies decaem em contato com a substância química;

- O princípio ativo da substância se degrada com o tempo.

O trabalho será apresentado da seguinte maneira: na Seção 2, apresentamos a formulação do modelo, as equações que descrevem a fase de dispersão e reação; os resultados das simulações serão apresentados na Seção 3 e finalmente, as conlusões são discutidas na Seção 4.

\section{Formulação do Modelo}

\subsection{Estágio de Dispersão}

\subsubsection{Movimentação da substância química}

Para a componente de difusão do movimento da substância química, consideramos que uma fração constante da concentração química , $0<\lambda<1$, é uniformemente distribuída entre os quatro vizinhos mais próximos. Vamos também considerar que o vento sopra da esquerda do domínio para a direita de modo que, a cada etapa de tempo, uma fração $0<\epsilon<1$ da substância química é levada pelo vento do sítio $(i, j)$ para o sítio $(i+1, j)$. Notemos que $\lambda$ e $\epsilon$ devem satizfazer $0 \leq \lambda+\epsilon \leq 1$. Assim, a concentração da substância química no sítio $(i, j)$, após o estágio de movimentação na geração t, é dado por

$$
c_{i, j}^{\prime}=(1-\lambda-\epsilon) c_{i, j}^{t}+\sum_{(r, s) \in V_{(i, j)}} \frac{\lambda}{4} c_{r, s}^{t}+\epsilon c_{i-1, j}^{t}
$$

onde $c_{i, j}^{\prime}$ representa a densidade da substância química após o estágio de dispersão no tempo t e $V_{(i, j)}=\{(i-1, j),(i+1, j),(i, j-1),(i, j+1)\}$ é a vizinhança de Neuman do sítio $(i, j)$.

O primeiro termo da equação (1) representa a concentração de substância química que permaneceu no sítio $(i, j)$ após a movimentação, o segundo termo descreve a concentração que se movimentou para o sítio $(i, j)$ por difusão e o terceiro termo representa a densidade recebida pelo sítio $(i, j)$ carregada pelo vento. 


\subsubsection{Movimentação da presa e do predador na ausência da substância química}

Supomos que presas e predadores locomovem-se por difusão na ausência de substância química, isto é, frações constantes de presas e predadores, $\mu_{h}$ e $\mu_{p}$, respectivamente, se distribuem uniformemente entre os quatro sítios mais próximos em cada etapa de tempo. Do ponto de vista macroscópico, o resultado é um fluxo de indivíduos de sítios com altas densidades para sítios com menores densidades. Dessa forma, as equações para as densidades de presas e predadores no sítio $(i, j)$ após a movimentação são

$$
\left\{\begin{array}{l}
h_{i, j}^{\prime}=\left(1-\mu_{h}\right) h_{i, j}^{t}+\frac{\mu_{h}}{4} \sum_{(r, s) \in V_{(i, j)}} h_{r, s}^{t} \\
p_{i, j}^{\prime}=\left(1-\mu_{p}\right) p_{i, j}^{t}+\frac{\mu_{p}}{4} \sum_{(r, s) \in V_{(i, j)}} p_{r, s}^{t}
\end{array}\right.
$$

onde, $h_{i, j}^{\prime}$ e $p_{i, j}^{\prime}$ são as densidades de presas e predadores no sítio $(i, j)$ após a movimentação, respectivamente.

Os primeiros termos das equações correspondem às densidades de indivíduos que permaneceram no sítio $(i, j)$ após a movimentação e os segundos termos descrevem a densidade de indivíduos recebidos pelo sítio $(i, j)$ vindos dos quatro vizinhos mais próximos.

\subsubsection{Movimentação da presa e do predador na presença da substância química}

Quando o pesticida é aplicado a um sítio, os indivíduos que sobreviveram fogem da substância e abandonam o sítio. Neste caso, uma fração de presas e de predadores, proporcional à concentração do químico, é distribuída uniformemente nos quatro sítios vizinhos. Assim, $c_{i, j}^{t} h_{i, j}^{t}$ presas e $c_{i, j}^{t} p_{i, j}^{t}$ predadores deixam o sítio $(i, j)$ em que foi aplicado pesticida. Do ponto de vista macroscópico, o fluxo líquido de indivíduos se dá para sítios com menor concentração de substância química.

Essas considerações nos levam às seguintes equações para as densidades de presas e predadores no sítio $(i, j)$ após a movimentação por fuga do pesticida

$$
\left\{\begin{array}{l}
h_{i, j}^{\prime}=\left(1-c_{i, j}^{t}\right) h_{i, j}^{t}+\sum_{(r, s) \in V_{(i, j)}} \frac{\lambda}{4} c_{r, s}^{t} h_{i, j}^{t} \\
p_{i, j}^{\prime}=\left(1-c_{i, j}^{t}\right) p_{i, j}^{t}+\sum_{(r, s) \in V_{(i, j)}} \frac{\lambda}{4} c_{r, s}^{t} p_{i, j}^{t}
\end{array}\right.
$$

onde $h_{i, j}^{\prime}$ e $p_{i, j}^{\prime}$ são as densidades de presas e predadores no sítio $(i, j)$ após a movimentação, respectivamente.

O primeiro termo de cada equação do sistema (2) representa a densidade de indivíduos que permaneceram no sítio de origem após a movimentação enquanto o segundo termo de cada equação descreve a proporção de indivíduos que migraram para o sítio $(i, j)$ for fuga de um sítio com pesticida.

\subsection{Fase de reação}

Durante a fase de reação ocorrem o crescimento das populações e a mortalidade das espécies em virtude da aplicação do pesticida. As presas crescem segundo a lei de Ricker, isto é, na ausência dos predadores, atingem sua capacidade suporte $K$. Os encontros entre as duas espécies beneficiam a população de predadores e diminuem a população de presas.

Quando a densidade de presas fica acima do limiar de dano $k$ no sítio $(i, j)$, a concentração de pesticida neste sítio é elevada a um. A substância química, nociva às duas espécies, diminui a densidade de presas e predadores e, por outro lado, perde sua eficácia exponencialmente. 
Assim, a fase de reação é descrita por

$$
\left\{\begin{array}{l}
H_{t+1}=H_{t} \exp \left(a\left(1-\left(\frac{H_{t}}{K}\right)\right)-f P_{t}-\alpha C_{t}\right) \\
P_{t+1}=d H_{t} P_{t} \exp \left(-\alpha C_{t}\right) \\
C_{t+1}=\beta C_{t}
\end{array}\right.
$$

onde, $H_{t}, P_{t}$ e $C_{t}$ são as densidades de presas, predadores e substância química, respectivamente, no tempo t. $\alpha$ é a eficiência do químico, isto é, $\frac{1}{\alpha}$ é a concentração da substância química necessária para reduzir significativamente a densidade das espécies. $\beta$ descreve a degradação natural do químico, $0<\beta<1$, isto é, quanto maior o valor de $\beta$ mais lenta é a degradação natural da substância química.

Vamos adimensionalizar o sistema (3) através da mudança de variáveis: $H_{t}=K h_{t}, P_{t}=\frac{p_{t}}{f}$ e $C_{t}=\frac{c_{t}}{\alpha}$. Obtemos assim, o sistema

$$
\left\{\begin{array}{l}
h_{t+1}=h_{t} \exp \left(a\left(1-h_{t}\right)-p_{t}-c_{t}\right) \\
p_{t+1}=b h_{t} p_{t} \exp \left(-c_{t}\right) \\
c_{t+1}=\beta c_{t}
\end{array}\right.
$$

onde $b=d K$.

Na ausência de substância química os pontos de equilíbrios do sistema (5) são:

- $\left(h_{0}, p_{0}\right)=(0,0)$ de extinção das espécies,

- $\left(h_{1}, p_{1}\right)=(1,0)$ de extinção dos predadores e

- $\left(h^{*}, p^{*}\right)=\left(\frac{1}{b}, a\left(1-\frac{1}{b}\right)\right)$ de coexistência das espécies.

\section{Simulações}

Consideramos um domínio $30 \times 30$ com condições de fronteiras absorventes, isto é, indivíduos que deixam o domínio são desconsiderados. No tempo inicial não há substância química e presas e predadores têm densidade aleatória em cada sítio com uma variação de $80 \%$ em torno do valor equilíbrio de coexistência.

$\mathrm{Na}$ ausência de pesticida, presas e predadores locomovem-se segundo a movimentação descrita no sistema (2). No entanto, se o químico estiver presente em um sítio, os indivíduos fogem de acordo com (3). A substância química, quando presente, se dispersa como descrito em (1). Ocorre então a fase de reação, e as equações (5) são aplicadas a todos os sítios do domínio. Se $h(i, j)>k$, isto é, se a densidade de presas for maior que o limiar de dano, então $c(i, j)=1$.

Fixamos os parâmetros de reação $a=1,9$ e $b=1,4$ dentro da região de estabilidade do ponto de coexistência das espécies e os coeficientes de difusão de presas e predadores $\mu_{h}=0,1$ e $\mu_{p}=0,9$ escolhidos levando em conta que os predadores se movimentam mais rapidamente do que as presas. Além disso, consideramos a difusividade do químico $\lambda=0,4$, a intensidade do vento $\epsilon=0,4$ e a taxa de degradação natural da substância, $\beta=0,9$. Realizamos simulações variando o limiar de controle de presas $k$. A Figura 1 ilustra as populações totais de presas (Fig. 1(a)) e predadores (Fig. 1(b)), bem como a concentração total de pesticida (Fig. 1(c)) para os seguintes casos: $k=1$ (curvas pretas), $k=h^{*}$ (curvas cinza escuro) e $k=0.7 h^{*}$ (curvas cinza claro). A Figura 2 mostra a distribuição espacial de presas (Fig. 2(a)), predadores (Fig. 2(b)) e da substância química (Fig. 2(c)), no tempo $t=50$.

Observamos a persistência de presas e predadores quando $k=1$ com distribuições espaciais caóticas (Fig.2 (a) e (b)). As densidade totais das espécies e a concentração do químico necessária para controlar a população de presas diminui com o tempo. 
Figura 1: (a) Densidade total de presas; $(b)$ Densidade total de predadores ; $(c)$ Densidade total de substância química, respectivamente. Para $a=1.9, b=1.4, \mu_{h}=0.1, \mu_{p}=0.9, \beta=0.9 \mathrm{e}$ limiar de controle de presas $k=1$ (curva preta), $k=h^{*}$ (curva cinza escura) e quando $k=0.7 h^{*}$ (curva cinza clara).

Figura 2: (a) Distribuição espacial de presas; (b) Distribuição espacial de predadores ; $(c)$ Distribuição espacial de substância química, respectivamente. Para $a=1.9, b=1.4, \mu_{h}=0.1$, $\mu_{p}=0.9, \beta=0.9$ e limiar de controle de presas $k=1$

Para $k=h^{*}$, isto é, somente será efetivado o uso de substância química para ajudar no controle das presas quando sua densidade for maior do que $\frac{1}{b}$, observamos que a população de predadores vai à extinção muito rapidamente. A densidade total de presas apresenta oscilações e, neste caso, é necessário uma concentração maior de substância química para que o controle seja feito.

Quando a substância química é lançada somente nos sítios em que a densidade de presas for maior do que $k=0.7 h^{*}$ observamos novamente a extinção dos predadores. A densidade total de presas apresenta oscilações de pequena amplitue mas a concentração total de químico necessária é ainda maior.

\section{Conclusões}

Neste trabalho propomos um modelo do tipo Redes de Mapas Acoplados para estudar um sistema presa-predador no qual a presa é uma praga e o predador é um agente de controle biológico. Consideramos que a estratégia de controle biológico da praga é combinada com o uso racional e planejado de pesticidas. Isto é, a substância química é utilizada apenas quando a densidade de presas atinge o limiar de dano. Além disso, a aplicação do químico é feita apenas do sítio de alta infestação da praga. Propomos regras para as fases de movimentação e de reação e por fim, apresentamos simulaçoes para diferentes valores do limiar de dano.

À medida que diminuímos o limiar da densidade de presas para aplicação da substância química, observamos que a mortalidade de presas é maior e, em consequência disso, ocorre a extinção de predadores. Por outro lado, a concentração do inseticida necessária para o controle 
eficiente das presas é cada vez maior.

Apesar de ser um modelo bastante simples, ele pode ser facilmente modificado para analisar diferentes estratégias como uso integrado de repelentes e movimentações não local das espécies na fuga da substância química. As ideias desenvolvidas neste trabalho podem ser usadas para uma melhor aplicação de pesticidas nas lavouras ou para um controle biológico mais eficaz.

\section{Referências}

[1] Hassell, M.P., Comins, H.N., May, R.M.. Spatial structure and chaos in insect population dynamics. Nature 353(1991) 255-258.

[2] Nerio, L.S., Olivero-Verbel, J., Stashenko, E.. Repellent activity of essential oils: a review. Bioresource Technology 101 (2010) 372-378.

[3] Rodrigues, L.A.D., Varriale, M.C., Godoy, W.A.C., Mistro, D.C..Spatiotemporal dynamics of an insect population in response to chemical substances. Ecological complexity 358 (2012). 